\title{
The Plant Growth-Promoting Bacteria Azospirillum amazonense: Genomic Versatility and Phytohormone Pathway
}

\author{
Ricardo Cecagno, ${ }^{1}$ Tiago Ebert Fritsch, ${ }^{1}$ and Irene Silveira Schrank ${ }^{1,2}$ \\ ${ }^{1}$ Centro de Biotecnologia, Laboratório de Microrganismos Diazotróficos, Universidade Federal do Rio Grande do Sul (UFRGS), \\ Porto Alegre, RS, Brazil \\ ${ }^{2}$ Departamento de Biologia Molecular e Biotecnologia, Instituto de Biociências, Universidade Federal do Rio Grande do Sul (UFRGS), \\ CP 15005, 91501-970 Porto Alegre, RS, Brazil
}

Correspondence should be addressed to Irene Silveira Schrank; irene@cbiot.ufrgs.br

Received 2 July 2014; Revised 24 October 2014; Accepted 24 October 2014

Academic Editor: You-Ping Deng

Copyright (C) 2015 Ricardo Cecagno et al. This is an open access article distributed under the Creative Commons Attribution License, which permits unrestricted use, distribution, and reproduction in any medium, provided the original work is properly cited.

\begin{abstract}
The rhizosphere bacterium Azospirillum amazonense associates with plant roots to promote plant growth. Variation in replicon numbers and rearrangements is common among Azospirillum strains, and characterization of these naturally occurring differences can improve our understanding of genome evolution. We performed an in silico comparative genomic analysis to understand the genomic plasticity of $A$. amazonense. The number of $A$. amazonense-specific coding sequences was similar when compared with the six closely related bacteria regarding belonging or not to the Azospirillum genus. Our results suggest that the versatile gene repertoire found in A. amazonense genome could have been acquired from distantly related bacteria from horizontal transfer. Furthermore, the identification of coding sequence related to phytohormone production, such as flavin-monooxygenase and aldehyde oxidase, is likely to represent the tryptophan-dependent TAM pathway for auxin production in this bacterium. Moreover, the presence of the coding sequence for nitrilase indicates the presence of the alternative route that uses IAN as an intermediate for auxin synthesis, but it remains to be established whether the IAN pathway is the Trp-independent route. Future investigations are necessary to support the hypothesis that its genomic structure has evolved to meet the requirement for adaptation to the rhizosphere and interaction with host plants.
\end{abstract}

\section{Introduction}

The genus Azospirillum comprises free-living, nitrogen-fixing bacteria that are known as plant growth-promoting rhizobacteria (PGPR), which can colonize, by adhesion, the root surface or the intercellular spaces of the host plant roots. The potential role of the PGPR in association with economically important cereals and other grasses is to promote plant growth by several mechanisms including nitrogen fixation and phytohormone production [1]. Several species of Azospirillum are able to secrete phytohormones such as auxins, gibberellins, cytokinins, and nitric oxide as signals of plant growth promotion $[2,3]$.

Azospirillum genomes, as previously suggested for various strains, are larger and are comprised of multiple replicons indicating a potential for genome plasticity [4]. Genomic rearrangements can occur spontaneously where replicons can be lost upon the formation of new megaplasmids $[5,6]$. Moreover, genome sequencing of some Azospirillum species revealed that significant part of the genome has been horizontally acquired [6]. Up until now, 16 Azospirillum species have been characterized; however complete genomic sequences of only Azospirillum brasilense, Azospirillum lipoferum, Azospirillum sp. B510, and a draft of Azospirillum amazonense genome have been published [7].

Azospirillum amazonense was found to be associated with the roots and rhizosphere of several grasses including sugarcane, maize, sorghum, and rice revealing a broad ecological distribution in Brazil. Studies revealed that A. amazonense is phylogenetically closer to Rhodospirillum centenum and Azospirillum irakense than to $A$. brasilense. Unlike other Azospirillum strains, A. amazonense can grow in the presence 
of sucrose as sole carbon source and is also better adapted to soil acidity, which offers the bacterium additional advantages for colonization of plant root tissue in acid environments [8, 9]. Moreover, A. amazonense genomic analyses revealed the presence of genes not commonly distributed in other Azospirillum species such as those responsible for the utilization of salicin as carbon source (similar to A. irakense) and a gene cluster (RubisCO) implicated in carbon fixation (A. lipoferum is able to grow autotrophically by means of RubisCO, but the presence of the genes has not yet been demonstrated) [7]. However, our understanding of phytohormone production in A. amazonense is still incomplete.

The genomic plasticity of $A$. amazonense is probably related to the versatile gene repertoire present in the genome of this bacterium suggesting that horizontal gene transfer may have an impact on the adaptation and evolution of this species. Gene organization and phylogenetic analysis demonstrated that genes coding for proteins responsible for the nitrogen fixation process, carbon fixation (RubisCOs), and molecular hydrogen oxidation (hydrogenases) is more closely related to Rhizobiales members than to related species [7].

To further examine the importance of A. amazonense genetic variability, an in silico comparative genomic analysis using subtractive hybridization was performed using total coding sequences (CDS) from A. amazonense to compare with genomes of closely related bacteria. The analysis of conserved and specific $A$. amazonense coding sequences indicated features that distinguished $A$. amazonense from other Azospirillum species. Furthermore, the specific interesting features related to phytohormone production may provide several cues to establish $A$. amazonense pathways for auxin biosynthesis.

\section{Material and Methods}

2.1. Bacteria Selection and Genome Access. We have previously generated a good quality draft genome sequence of the A. amazonense Y2 (ATCC 35120) strain [7]. In this paper, the draft genome sequences were annotated and analyzed for the presence of specific regions, and during the BLAST search best-hits were detected with different bacteria, such as Rhodospirillum, Azospirillum, Bradyrhizobium, and Caulobacter.

Therefore, the A. amazonense comparative genomic analyses were performed using bacterial genomes including six species for which publicly closed genomes were available (Table 1). All genomes were downloaded from NCBI on January 10, 2013. The accession numbers used in this study are Azospirillum amazonense Y2 PRJNA73583, PRJNA65263; Azospirillum sp. B510 projects PRJNA46085, PRJDA32551; Azospirillum brasilense Sp245 PRJEA162161, PRJEA70627; Azospirillum lipoferum 4B PRJNA82343, PRJEA50367; Rhodospirillum centenum SW project PRJNA58805; Bradyrhizobium japonicum USDA 110 projects PRJNA57599 and PRJNA17; and Caulobacter segnis ATCC 21756 project PRJNA41709.
TABLE 1: General features for the bacteria genomes used in the comparative analysis.

\begin{tabular}{|c|c|c|c|}
\hline Bacteria & $\begin{array}{l}\text { Genome } \\
\text { size }\end{array}$ & $\begin{array}{c}\text { Total number of } \\
\text { CDS }\end{array}$ & $\begin{array}{c}\text { Assembly } \\
\text { reference } \\
\text { number }\end{array}$ \\
\hline $\begin{array}{l}\text { Azospirillum } \\
\text { amazonense }\end{array}$ & $7,044,835$ & $3,319^{*}$ & ASM22599v] \\
\hline $\begin{array}{l}\text { Azospirillum } \\
\text { brasilense }\end{array}$ & $7,530,241$ & 7,557 & ASM23736vl \\
\hline $\begin{array}{l}\text { Azospirillum } \\
\text { lipoferum }\end{array}$ & $6,846,400$ & 6,093 & ASM28365vl \\
\hline $\begin{array}{l}\text { Azospirillum sp. } \\
\text { B510 }\end{array}$ & $7,599,738$ & 6,309 & ASM1072vl \\
\hline $\begin{array}{l}\text { Rhodospirillum } \\
\text { centenum }\end{array}$ & $4,355,543$ & 4,003 & ASM1618v1 \\
\hline Caulobacter segnis & $4,655,622$ & 4,139 & ASM9228v1 \\
\hline $\begin{array}{l}\text { Bradyrhizobium } \\
\text { japonicum }\end{array}$ & $9,105,828$ & 8,317 & ASM1136v1 \\
\hline
\end{tabular}

${ }^{*}$ The total number of A. amazonense CDS was published by Sant'Anna et al. 2011 [7].

2.2. Annotation and Subtractive Hybridization. Reannotation of $A$. amazonense protein-coding genes was performed with a following procedure, which consists of two phases: initially the A. amazonense contigs were compared with the Azospirillum sp. B510 genome followed by functional annotation of each coding sequence (CDS) based on comparison with known sequences of the other six selected genomes using the Xbase Annotation Service [10]. All coding sequences predictions were manually checked for conservation in case of multiple hits, and only the alignments with best-hit results were selected from each genome. Information related to Cluster of Orthologous Group and KEGG pathway was added to the annotation using the server for metagenomic analysis (WebMGA) [11]. Annotation was based on comparison to protein clusters and on the BLAST results.

The subtractive hybridization using the mGenomeSubtractor program [12] was applied to run BLAST searches of the $A$. amazonense genome against multiple bacterial genomes for in silico comparative genomic analyses in order to characterize the unique sequences of $A$. amazonense. Proteins possibly related to phytohormones were analyzed in the Arabidopsis Hormone Database (AHD) [13], and proteins with homology $(H)$ values more than 0.1 were arbitrarily defined as conserved coding sequences.

\section{Results and Discussion}

3.1. Comparative Analyses and Specific Protein Coding Sequences. The draft genome sequence of $A$. amazonense consists of 7,044,835 bp with 3,319 predicted coding sequences (CDS) where 2,299 have similarity with genes with known functions and 1,020 codes for hypothetical proteins or proteins of unknown function [7]. Although the estimated coverage of the genome was $35 \mathrm{x}$, the number of predicted coding sequences was lower when compared with the other 
species of Azospirillum where the total number of coding sequences ranges from 6,093 to 7,557 (Table 1).

In order to clarify the genomic coding sequences content of $A$. amazonense, two alternative comparative approaches using the Xbase Annotation Service were performed. Initially, to assess the coverage of the predicted gene repertoires a BLAST search was performed with only the Azospirillum sp. B510 genome. The total number of predicted protein-coding genes was 5,496 of which 2,165 were annotated as proteins of unknown function or hypothetical proteins. These numbers are similar to what is found in A. lipoferum and Azospirillum sp. B510 (Table 1). These results including the 5,496 sequences can be accessed using the http://www.xbase.ac.uk/annotation/ results/rWn50Rn6LVRucf55SWfsvHfoqdpmd655/.

The second approach used an A. amazonense-vs-all (six selected genomes) BLAST to examine the overall similarity of the A. amazonense genome with closely related bacteria, and the results are shown in Table 2. The whole-genome comparisons revealed that the number of coding sequences found to be conserved and characterized as best-hits varied in each bacterium, from 3,126 (present in Azospirillum sp. B510) and 1,508 (present in Rhodospirillum centenum) to 2,846 (present in $R$. centenum) and 440 proteins (present in A. lipoferum), respectively. It is important to point out that the majority of the orthologs showing best-hit results were found with the $R$. centenum genome supporting previous suggestions of a close evolutionary relationship between $A$. amazonense and $R$. centenum $[7,14]$. Interestingly, the number of coding sequences with best-hits orthologs found in the other Azospirillum species is almost equivalent to those found in the genome of bacteria from other genera, such as Bradyrhizobium japonicum and Caulobacter segnis (Table 2).

These unexpected results may support previous reports related with the genome repertoire of $A$. amazonense where horizontal gene transfer may be one of several events that result in an intragenera genomic plasticity. Phylogenetic analysis indicated the close relationship of the A. amazonense enzymes encoded by the gene cluster related to carbon fixation (RubisCo) and by genes related to nitrogen fixation (nif) processes with those from some species of the order Rhizobiales. Moreover, some features, such as the genetic organization of the carbon-fixation cluster and of the nif cluster of A. amazonense, are similar to the homolog cluster of the Bradyrhizobium species [7].

In conclusion, from the total 5,496 CDS found in the A. amazonense genome approximately half of the coding sequences have an ortholog in other closely related bacteria. However, using this methodology's numbers varying from 2,370 to 2,650 CDS showed lower degrees of similarity ( $E$ value $>10^{-10}$ ) with coding sequences present in the genome of the compared bacteria.

Comparative genomic analysis using in silico subtractive hybridization allowed searching for specific proteins of the A. amazonense genome against multiple closely related bacterial genomes. Therefore, to determine the possible differences between the $A$. amazonense genome and each of the selected six closely related genomes, an in silico subtractive
TABLE 2: Predicted distribution of coding sequences (CDS) in $A$. amazonense draft genome and in the complete genome of other bacteria.

\begin{tabular}{lccc}
\hline Comparisons & \multicolumn{2}{c}{ Conserved CDS } & Specific \\
& Best-hits & Total number & CDS \\
\hline $\begin{array}{l}\text { A. a. versus Azospirillum } \\
\text { brasilense }\end{array}$ & 583 & 3,031 & 2,465 \\
$\begin{array}{l}\text { A. a. versus Azospirillum } \\
\text { lipoferum }\end{array}$ & 440 & 3,084 & 2,412 \\
$\begin{array}{l}\text { A. a. versus Azospirillum } \\
\text { sp. B510 }\end{array}$ & 533 & 3,126 & 2,370 \\
$\begin{array}{l}\text { A. a. versus } \\
\text { Rhodospirillum } \\
\text { centenum }\end{array}$ & 1,508 & 2,846 & 2,650 \\
$\begin{array}{l}\text { A. a. versus Caulobacter } \\
\text { segnis }\end{array}$ & 711 & 2,852 & 2,644 \\
$\begin{array}{l}\text { A. a. versus } \\
\text { Bradyrhizobium }\end{array}$ & & & \\
japonicum & 632 & 2,970 & 2,526 \\
\hline
\end{tabular}

A. a.: Azospirillum amazonense.

Protein coding sequences with $E$ value $>10-10$ were considered specific CDS (using the Xbase Annotation Service).

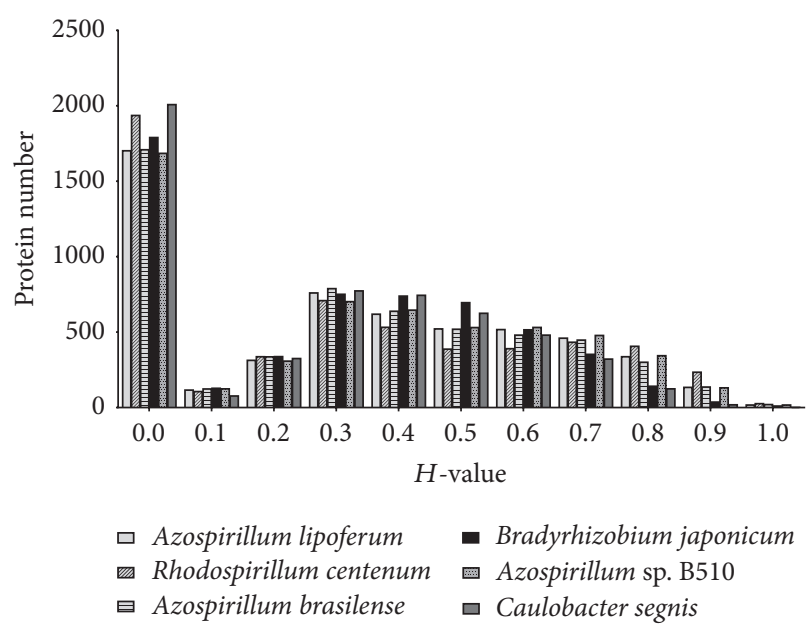

FIGURE 1: Histogram distribution of predicted proteins in A. amazonense compared with six closely related genomes using BLASTPbased homology value ( $H$ value). The $H$-value reflects the degree of similarity in terms of length of match and the degree of identity at amino acid level between the matching CDS in the subject genome and the query CDS examined with $E$ value $>10^{-8}$.

hybridization technique was applied. The histogram of $H$ values (Figure 1) was used to set the cutoff to discriminate between $A$. amazonense-specific and conserved coding sequences. Proteins with homology $(H)$ values of less than 0.42 and more than 0.64 were arbitrarily defined as specific and conserved coding sequences, respectively [12]. This cutoff value was proposed by Shao et al. [12] and has been used in comparative genomic analyses to differentiate strains of pseudomonads $[12,15]$ or to compare genomes of species from the genus Erwinia [16]. 
TABLE 3: Numbers of specific proteins for A. amazonense genome against six closely related genomes.

\begin{tabular}{lccc}
\hline \multirow{2}{*}{ Comparisons } & \multicolumn{3}{c}{ A. amazonense } \\
& $\begin{array}{c}\text { Specific } \\
\text { CDS }\end{array}$ & $\begin{array}{c}\text { Conserved } \\
\text { CDS }\end{array}$ & $\begin{array}{c}\text { Other } \\
\text { CDS }\end{array}$ \\
\hline Azospirillum brasilense & 3,689 & 948 & 859 \\
Azospirillum lipoferum & 3,606 & 746 & 1,144 \\
Azospirillum sp. B510 & 3,571 & 793 & 1,132 \\
Rhodospirillum centenum & 3,697 & 770 & 1,029 \\
Caulobacter segnis & 4,043 & 382 & 1,071 \\
Bradyrhizobium japonicum & 3,880 & 317 & 1,299 \\
\hline
\end{tabular}

The in silico subtractive hybridization analysis was performed with $A$. amazonense total coding sequences (CDS) against the proteins from the six genomes.

Proteins with homology $(H)$ value less than 0.42 and more than 0.64 were arbitrarily defined as specific and conserved CDS, respectively, and other CDS were defined with $H$ values between 0.42 and 0.64 .

The subtractive hybridization approach revealed different profiles in gene number of specific and conserved proteins for the A. amazonense genome against the six others (Table 3 ). The number of proteins found to be conserved varied in each bacterium, from 948 CDS in A. lipoferum to 317 CDS in $B$. japonicum. Interestingly, the number of $A$. amazonensespecific proteins was similar when compared with the six bacteria varying from 4,043 (C. segnis) to 3,571 (Azospirillum sp. B510). Moreover, the specific proteins vary among the Azospirillum genomes analyzed from 3,571 to 3,689 only, indicating that these coding sequences are unique to the A. amazonense genome. Analyses of Figure 1 show that the majority of specific proteins in $A$. amazonense have $H$ values less than 0.1, suggesting that Azospirillum species are evolutionally diverse. This is consistent with previous studies that had proposed that some regions of the genome of Azospirillum species were acquired from distantly related bacteria from horizontal transfer [6].

To further characterize the global profile of $A$. amazonense-specific coding sequences, an in silico subtractive hybridization comparative analysis was performed with total A. amazonense putative coding sequences versus all six genomes, simultaneously. A total of 142 conserved CDS and 2,483 specific CDS were identified (see Supplementary Table 1 in Supplementary Material available online at http://dx.doi.org/10.1155/2014/898592). For function classification and pathway assignment, all specific and conserved $A$. amazonense coding sequences were classified to 20 different functional classes based on Clusters of Orthologous Groups (COG) (Table 4). The comparison of the A. amazonense genome and the other six available closely related genomes with regard to the functional category revealed that 1,196 specific CDS from A. amazonense were distributed among the different classes of orthologous clusters and that 1,287 specific CDS were unclassified being considered hypothetical products.
TABle 4: Protein categories encoded by A. amazonense specific and conserved genes identified by in silico subtractive hybridization.

\begin{tabular}{|c|c|c|}
\hline CDS assigned function ${ }^{*}$ & $\begin{array}{l}\text { Specific } \\
\text { CDS }\end{array}$ & $\begin{array}{l}\text { Conserved } \\
\text { CDS }\end{array}$ \\
\hline Transcription & 143 & 11 \\
\hline Signal transduction mechanisms & 137 & 5 \\
\hline Inorganic ion transport and metabolism & 111 & 1 \\
\hline Carbohydrate transport and metabolism & 101 & 4 \\
\hline Cell wall/membrane/envelope biogenesis & 94 & 1 \\
\hline Amino acid transport and metabolism & 86 & 19 \\
\hline Energy production and conversion & 49 & 27 \\
\hline $\begin{array}{l}\text { Secondary metabolites biosynthesis, } \\
\text { transport, and catabolism }\end{array}$ & 47 & 3 \\
\hline Cell motility & 44 & 0 \\
\hline Coenzyme transport and metabolism & 41 & 4 \\
\hline Lipid transport and metabolism & 41 & 10 \\
\hline $\begin{array}{l}\text { Intracellular trafficking, secretion, and } \\
\text { vesicular transport }\end{array}$ & 37 & 1 \\
\hline Defense mechanisms & 34 & 0 \\
\hline Replication, recombination, and repair & 33 & 3 \\
\hline $\begin{array}{l}\text { Posttranslational modification, protein } \\
\text { turnover, and chaperones }\end{array}$ & 27 & 16 \\
\hline $\begin{array}{l}\text { Translation, ribosomal structure, and } \\
\text { biogenesis }\end{array}$ & 14 & 27 \\
\hline Nucleotide transport and metabolism & 12 & 12 \\
\hline $\begin{array}{l}\text { Cell cycle control, cell division, and } \\
\text { chromosome partitioning }\end{array}$ & 4 & 1 \\
\hline RNA processing and modification & 2 & 0 \\
\hline $\begin{array}{l}\text { General function prediction only or } \\
\text { function unknown }\end{array}$ & 352 & 11 \\
\hline
\end{tabular}

Proteins with homology $(H)$ value less than 0.42 and more than 0.64 were arbitrarily defined as specific and conserved CDS, respectively.

${ }^{*} \mathrm{CDS}$ assigned function was based on the COGs according to BLAST search.

Detailed analysis of the A. amazonense-specific CDS from Table 4 (and Supplementary Table 1) indicates special attention to the coding sequences classified in the Signal Transduction Mechanisms and Secondary Metabolites Biosynthesis, Transport and Catabolism functional class. Among the 137 CDS classified in the Signal Transduction Mechanisms functional category, there were protein coding sequences similar to cytokinins (ZP_08868173.1, ZP_08868457.1) and ethylene response (ZP_08867667.1) that could be related to phytohormone production (Supplementary Table 1). In particular, we have paid attention to a coding sequence related to lysine/ornithine N-monooxygenase (ZP_08869952.1) similar to flavin-containing monooxygenase from Arabidopsis thaliana (YUCCA9) involved in auxin synthesis in plants $[17,18]$ found in the Secondary Metabolites Biosynthesis, Transport and Catabolism functional class (Supplementary Table 1). Therefore, to better understand the auxin biosynthesis pathways in A. amazonense, studies attempting to define coding sequence related to phytohormone production were performed. 
3.2. Phytohormone Production Related Sequences. The improvement of plant growth upon Azospirillum inoculation is attributed, as one of many factors, to the production of auxin by these bacteria [19]. Indole-3-acetic acid (IAA) is considered the most important auxin implicated in different aspects of plant growth. In bacteria, the two most common routes for indole-3-acetic acid biosynthesis are the IAM (indole-3acetamide) and the IPyA (indole-3-pyruvate) pathways [20]. However, in A. brasilense, besides these two tryptophandependent pathways, an additional tryptophan-independent pathway was identified [21].

Similar to other Azospirillum species, A. amazonense, as typical plant-growth promoting rhizobacteria, stimulate root proliferation $[22,23]$. However, genes responsible for biosynthesis and secretion of phytohormones are poorly described in this species. Previous works on A. amazonense genome sequence and annotation were unable to localize genes related to the IAM or IPyA pathways (iaaM, iaaH, and $i p d C$ ) and were able to identify only the presence of a coding sequence similar to nitrilases responsible for the conversion of indole 3-acetonitrile (IAN) to IAA in plants [7]. Therefore, the presence of coding sequences homologous to nitrilase and to flavin-containing monooxygenase (this paper) suggests that $A$. amazonense could use alternative pathways closely related to those found in plants.

Biosynthetic pathways for IAA have been fully investigated and tryptophan-dependent and Trp-independent routes have been studied [20, 24, 25]. Although genes coding for proteins related to the bacterial common routes IAM (indole-3-acetamide route) and IPyA (indole-3-pyruvic route) was not found in the A. amazonense genome, the identification of flavin-monooxygenase and nitrilase enzymes suggests the presence of the TAM (tryptamine route) and IAN (indole-3-acetamide route) pathways for IAA synthesis in this bacterium (Figure 2). It is well known that nitrilases in plants (maize and Arabidopsis thaliana) and also in Bacillus amyloliquefaciens were shown to hydrolyze indole3 -acetonitrile (IAN) to IAA $[25,26]$. Moreover, evidence for the IAN and TAM pathways has been reported in A. brasilense [21].

Aiming to unveil the IAA pathways in A. amazonense, a search for other enzymes involving the TAM pathway was performed. The genome of $A$. amazonense contains an aldehyde oxidase-coding sequence (WP_004273557) homolog (query cover 91\%; 33\% identity; $E$ value $e-99$ ) to the $A$. thaliana AAO1 gene (AED92912) that is capable of oxidizing indole-3-acetaldehyde to indole-3-acetic acid with high efficiency [27]. Therefore, oxidation of indole-3-acetaldehyde by $A$. amazonense aldehyde oxidase is likely to represent the TAM route transforming indole-3-acetaldehyde (IAAld) to produce IAA phytohormone in this bacterium (Figure 2). To conclude, A. amazonense appears to possess only one regulated Trp-dependent route for IAA synthesis, the TAM pathway, while $A$. brasilense possesses two differently regulated routes, namely, the IPyA and the TAM pathways [21]. Furthermore, the alternative route that uses IAN as an intermediate, the IAN pathway, appears to be present in both species, but it remains to be established whether the IAN pathway is the Trp-independent route.

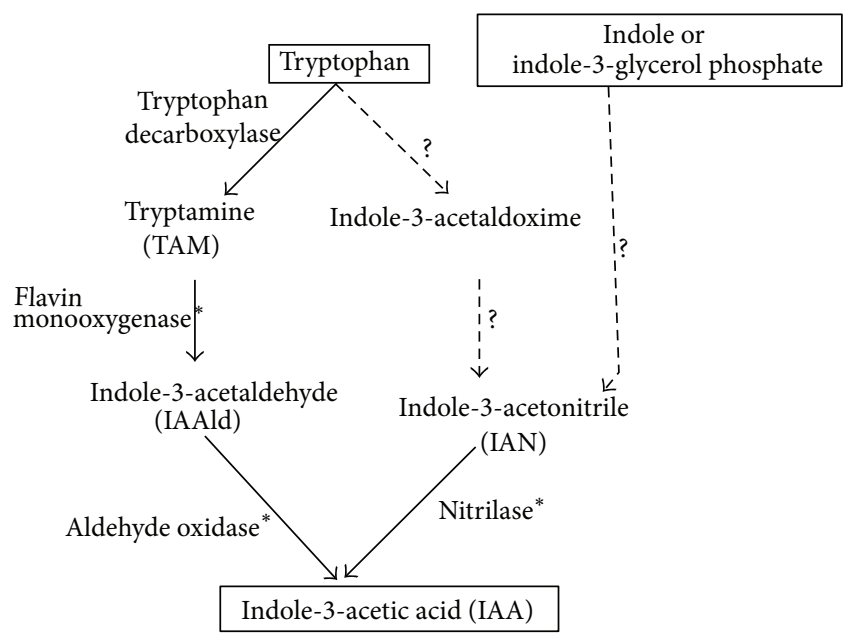

FIGURE 2: A. amazonense pathways of IAA biosynthesis. Tryptophan-dependent pathways or tryptophan-independent pathways (starting from indole or indole-3-glycerol phosphate) are indicated based on routes found in plants and bacteria. Enzymes indicated with an asterisk have been identified in A. amazonense, and routes indicated as dotted lines indicated that the precursor of IAN may or may not be tryptophan.

To further understand the phytohormone biosynthesis pathway in $A$. amazonense, an in silico comparative analysis was performed with total coding sequences from $A$. amazonense versus all proteins deposited in the Arabidopsis Hormone Database. Furthermore, the comparative analysis was also performed with coding sequences in the auxin response transcriptome data of $A$. brasilense [28]. A total of $54 \mathrm{~A}$. amazonense CDS revealed similarity with proteins related to hormone production in plants and bacterial auxin signal transduction pathways (Supplementary Table 1). The presence of these coding sequences suggests that IAA could be a signal that alters gene expression in A. amazonense similar to that found in A. brasilense [28]. Moreover, the genome of $A$. amazonense has coding sequences that could be related to other hormone pathways similar to those described for other Azospirillum species [19, 21].

Another beneficial effect provided by the association of soil bacteria with plants could be due to the plant hormone ethylene, which can inhibit plant growth by regulating several developmental aspects [29]. Similar to other plant growth-promoting rhizobacteria, a coding sequence homologous to 1-aminocyclopropane-1-carboxylate (ACC) deaminase (WP_004272971.1) has been identified in the A. amazonense genome. Previous reports have suggested that A. amazonense can stimulate plant growth by producing or metabolizing plant hormones and the presence of ACC deaminase which can hydrolyze ACC, the immediate precursor of the plant hormone ethylene, could be involved by lowering the plant ethylene levels and increasing plant growth. Moreover, the identification of the octaprenyl diphosphate synthase enzyme (ZP_08868744) could be related to cytokinin biosynthesis by a known hormone that affects plant growth and yield. Although the auxin hormone is considered a major 
class of hormones regulating plant growth, cytokinins or ethylene-related phytohormones could interact with auxin leading to root system development.

In conclusion, it appears that the rhizosphere bacterium A. amazonense is able to produce IAA through the tryptamine and indole-3-acetonitrile pathways and similar to $A$. brasilense could alter gene expression in response to the presence of auxin. Moreover, the role as plant-growthpromoting bacteria could be related to IAA production or to its ability to metabolize the ethylene precursor (ACC) and thereby increases the growth of the root system. Furthermore, the multiple genome comparison performed with $A$. amazonense and closely related bacteria supports previous evidence concerning $A$. amazonense genomic versatility and that several genes could have been acquired from distantly related bacteria [6]. Future investigation of $A$. amazonense is necessary to support the hypothesis that its genomic structures have evolved to meet the requirements for adaptation to the rhizosphere and interaction with host plants.

\section{Conflict of Interests}

The authors declare that there is no conflict of interests regarding the publication of this paper.

\section{Acknowledgments}

This work was supported by grants from the Brazilian National Research Council (CNPq) and the Fundação de Amparo à Pesquisa do Estado do Rio Grande do Sul (FAPERGS). R. Cecagno and T. E. Fritsch received scholarships from Coordenação de Aperfeiçoamento de Pessoal de Nível Superior (CAPES).

\section{References}

[1] Y. Bashan, G. Holguin, and L. E. de-Bashan, "Azospirillum-plant relationships: physiological, molecular, agricultural, and environmental advances (1997-2003)," Canadian Journal of Microbiology, vol. 50, no. 8, pp. 521-577, 2004.

[2] S. Fibach-Paldi, S. Burdman, and Y. Okon, "Key physiological properties contributing to rhizosphere adaptation and plant growth promotion abilities of Azospirillum brasilense," FEMS Microbiology Letters, vol. 326, no. 2, pp. 99-108, 2012.

[3] M. Kochar and S. Srivastava, "Surface colonization by Azospirillum brasilense SM in the indole-3-acetic acid dependent growth improvement of sorghum," Journal of Basic Microbiology, vol. 52, no. 2, pp. 123-131, 2012.

[4] C. C. G. Martin-Didonet, L. S. Chubatsu, E. M. Souza et al., "Genome structure of the genus Azospirillum," Journal of Bacteriology, vol. 182, no. 14, pp. 4113-4116, 2000.

[5] A. V. Shelud'ko, O. E. Varshalomidze, L. P. Petrova, and E. I. Katsy, "Effect of genomic rearrangement on heavy metal tolerance in the plant-growth-promoting rhizobacterium Azospirillum brasilense Sp245," Folia Microbiologica, vol. 57, no. 1, pp. 5-10, 2012.

[6] F. Wisniewski-Dyé, K. Borziak, G. Khalsa-Moyers et al., “Azospirillum genomes reveal transition of bacteria from aquatic to terrestrial environments," PLoS Genetics, vol. 7, no. 12, Article ID e1002430, 2011.
[7] F. H. Sant'Anna, L. G. P. Almeida, R. Cecagno et al., "Genomic insights into the versatility of the plant growth-promoting bacterium Azospirillum amazonense," BMC Genomics, vol. 12, article 409, 2011.

[8] F. M. Magalhães, J. I. Baldani, S. M. Souto, J. R. Kuykendall, and J. Dobereiner, "A new acid-tolerant Azospirillum species," Anais da Academia Brasileira de Ciências, vol. 55, pp. 417-430, 1983.

[9] J. I. Baldani and V. L. D. Baldani, "History on the biological nitrogen fixation research in graminaceous plants: special emphasis on the Brazilian experience," Anais da Academia Brasileira de Ciencias, vol. 77, no. 3, pp. 549-579, 2005.

[10] R. R. Chaudhuri, N. J. Loman, L. A. S. Snyder, C. M. Bailey, D. J. Stekel, and M. J. Pallen, "xBASE2: a comprehensive resource for comparative bacterial genomics," Nucleic Acids Research, vol. 36, no. 1, pp. D543-D546, 2008.

[11] S. Wu, Z. Zhu, L. Fu, B. Niu, and W. Li, "WebMGA: a customizable web server for fast metagenomic sequence analysis," $B M C$ Genomics, vol. 12, article 444, 2011.

[12] Y. Shao, X. He, E. M. Harrison et al., "mGenomeSubtractor: a web-based tool for parallel in silico subtractive hybridization analysis of multiple bacterial genomes," Nucleic Acids Research, vol. 38, no. 2, Article ID gkq326, pp. W194-W200, 2010.

[13] Z.-Y. Peng, X. Zhou, L. Li et al., "Arabidopsis hormone database: a comprehensive genetic and phenotypic information database for plant hormone research in Arabidopsis," Nucleic Acids Research, vol. 37, no. 1, pp. D975-D982, 2009.

[14] M. Stoffels, T. Castellanos, and A. Hartmann, "Design and application of new 16S rRNA-targeted oligonucleotide probes for the Azospirillum-Skermanella-Rhodocista-cluster," Systematic and Applied Microbiology, vol. 24, no. 1, pp. 83-97, 2001.

[15] M. Qi, D. Wang, C. A. Bradley, and Y. Zhao, "Genome sequence analyses of Pseudomonas savastanoi pv. glycinea and subtractive hybridization-based comparative genomics with nine pseudomonads," PLoS ONE, vol. 6, no. 1, Article ID e16451, 2011.

[16] Y. Zhao and M. Qi, "Comparative genomics of Erwinia amylovora and related Erwinia species-what do we learn?" Genes, vol. 2, no. 3, pp. 627-639, 2011.

[17] Y. Zhao, S. K. Christensen, C. Fankhauser et al., "A role for flavin monooxygenase-like enzymes in auxin biosynthesis," Science, vol. 291, no. 5502, pp. 306-309, 2001.

[18] Y. Zhao, "Auxin biosynthesis: a simple two-step pathway converts tryptophan to indole-3-Acetic acid in plants," Molecular Plant, vol. 5, no. 2, pp. 334-338, 2012.

[19] O. Ona, J. van Impe, E. Prinsen, and J. Vanderleyden, "Growth and indole-3-acetic acid biosynthesis of Azospirillum brasilense Sp245 is environmentally controlled," FEMS Microbiology Letters, vol. 246, no. 1, pp. 125-132, 2005.

[20] M. Lambrecht, Y. Okon, A. V. Broek, and J. Vanderleyden, "Indole-3-acetic acid: a reciprocal signalling molecule in bacteria-plant interactions," Trends in Microbiology, vol. 8, no. 7, pp. 298-300, 2000.

[21] R. Carreño-Lopez, N. Campos-Reales, C. Elmerich, and B. E. Baca, "Physiological evidence for differently regulated tryptophan-dependent pathways for indole-3-acetic acid synthesis in Azospirillum brasilense," Molecular and General Genetics, vol. 264, no. 4, pp. 521-530, 2000.

[22] O. Steenhoudt and J. Vanderleyden, "Azospirillum, a freeliving nitrogen-fixing bacterium closely associated with grasses: genetic, biochemical and ecological aspects," FEMS Microbiology Reviews, vol. 24, no. 4, pp. 487-506, 2000. 
[23] E. Rodrigues, L. Rodrigues, A. de Oliveira et al., “Azospirillum amazonense inoculation: effects on growth, yield and $\mathrm{N}_{2}$ fixation of rice (Oryza sativa L.)," Plant and Soil, vol. 316, no. 1-2, p. 323, 2009.

[24] B. Bartel, "Auxin biosynthesis," Annual Review of Plant Biology, vol. 48, no. 1, pp. 51-66, 1997.

[25] E. E. Idris, D. J. Iglesias, M. Talon, and R. Borriss, “Tryptophandependent production of Indole-3-Acetic Acid (IAA) affects level of plant growth promotion by Bacillus amyloliquefaciens FZB42," Molecular Plant-Microbe Interactions, vol. 20, no. 6, pp. 619-626, 2007.

[26] V. Kriechbaumer, W. J. Park, M. Piotrowski, R. B. Meeley, A. Gierl, and E. Glawischnig, "Maize nitrilases have a dual role in auxin homeostasis and $\beta$-cyanoalanine hydrolysis," Journal of Experimental Botany, vol. 58, no. 15-16, pp. 4225-4233, 2007.

[27] M. Seo, S. Akaba, T. Oritani et al., "Higher activity of an aldehyde oxidase in the auxin-overproducing superrootl mutant of arabidopsis thaliana," Plant Physiology, vol. 116, no. 2, pp. 687693, 1998.

[28] S. van Puyvelde, L. Cloots, K. Engelen et al., "Transcriptome analysis of the rhizosphere bacterium Azospirillum brasilense reveals an extensive auxin response," Microbial Ecology, vol. 61, no. 4, pp. 723-728, 2011.

[29] L. Chen, I. C. Dodd, J. C. Theobald, A. A. Belimov, and W. J. Davies, "The rhizobacterium Variovorax paradoxus 5C-2, containing ACC deaminase, promotes growth and development of Arabidopsis thaliana via an ethylene-dependent pathway," Journal of Experimental Botany, vol. 64, no. 6, pp. 1565-1573, 2013. 

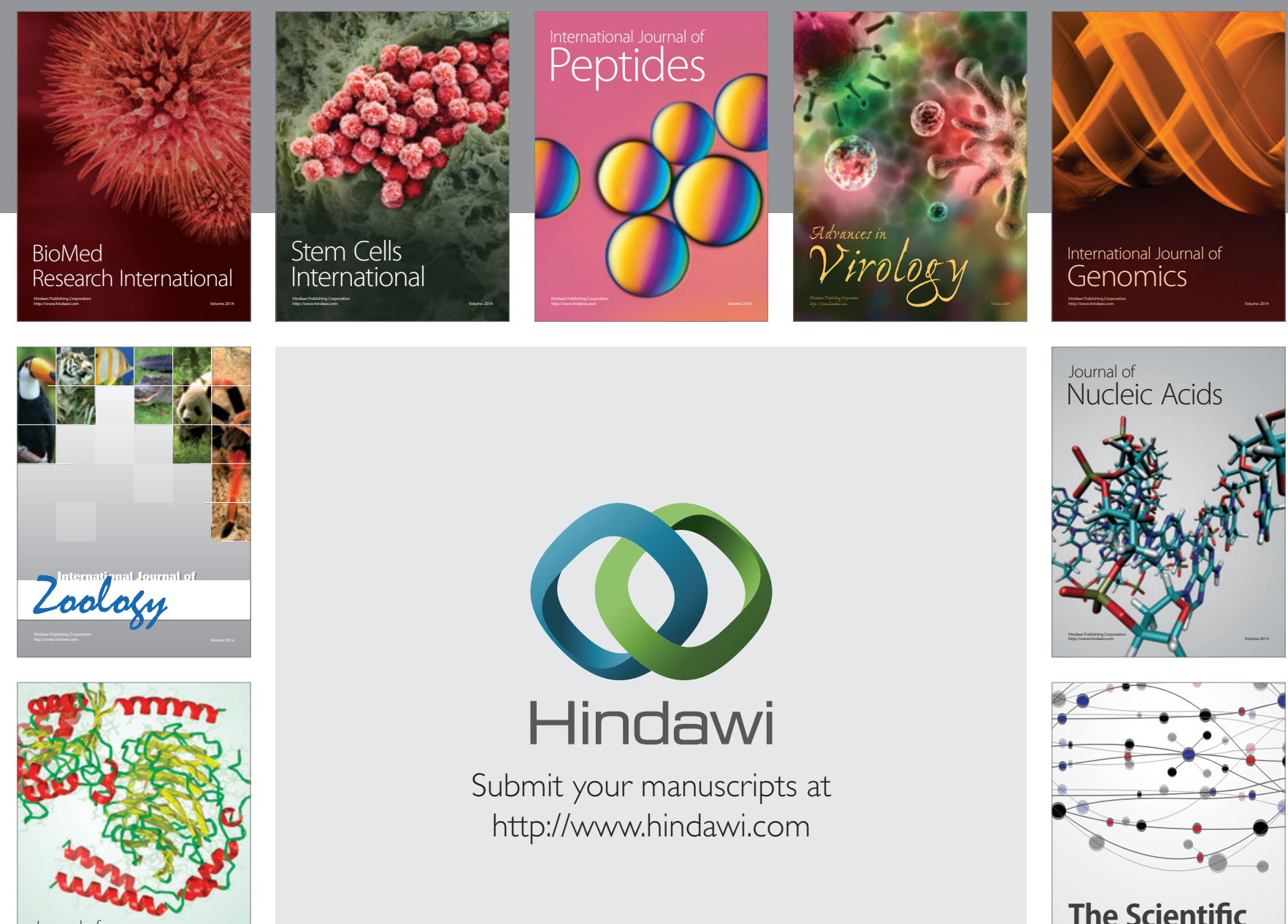

Submit your manuscripts at

http://www.hindawi.com

Journal of
Signal Transduction
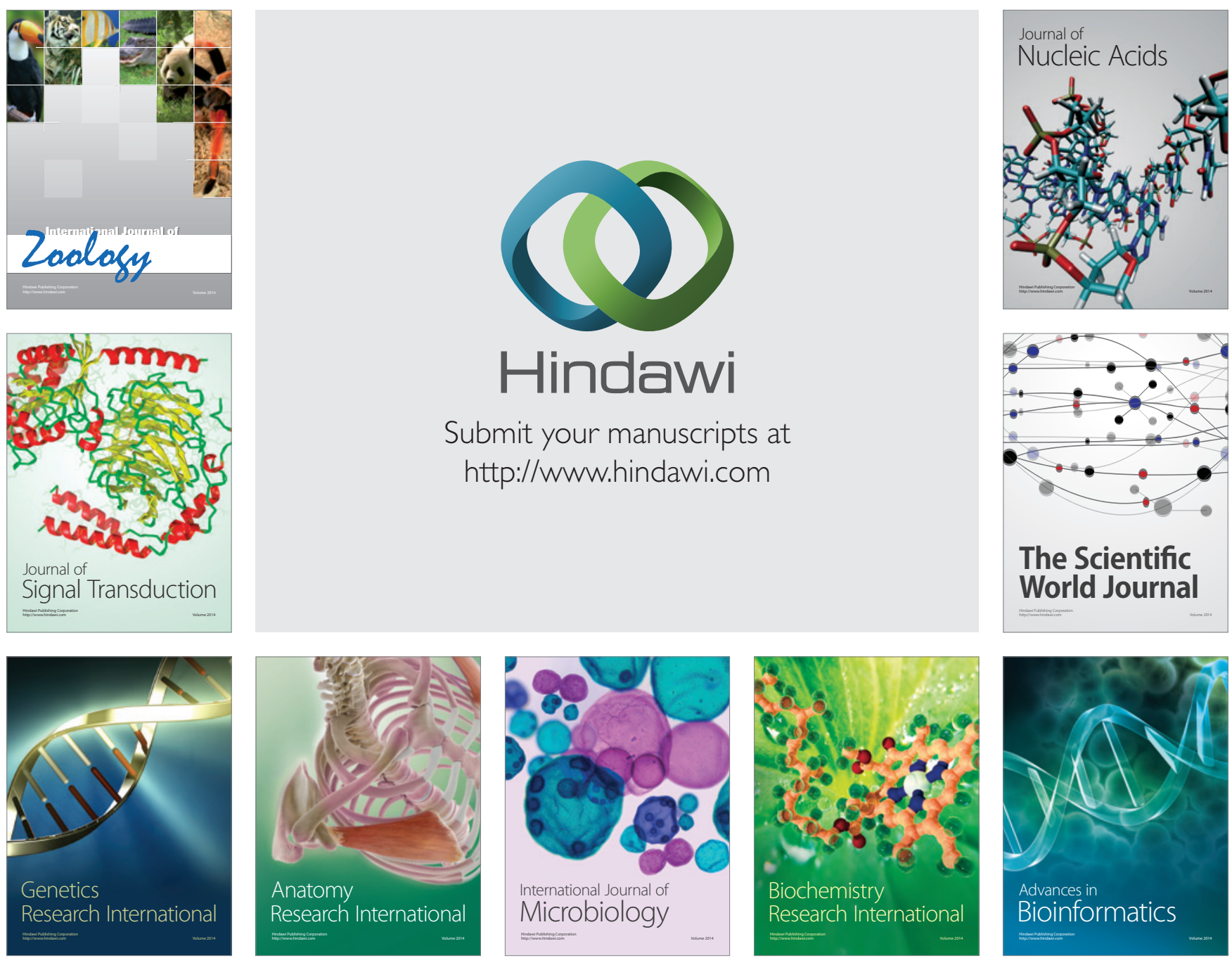

The Scientific World Journal
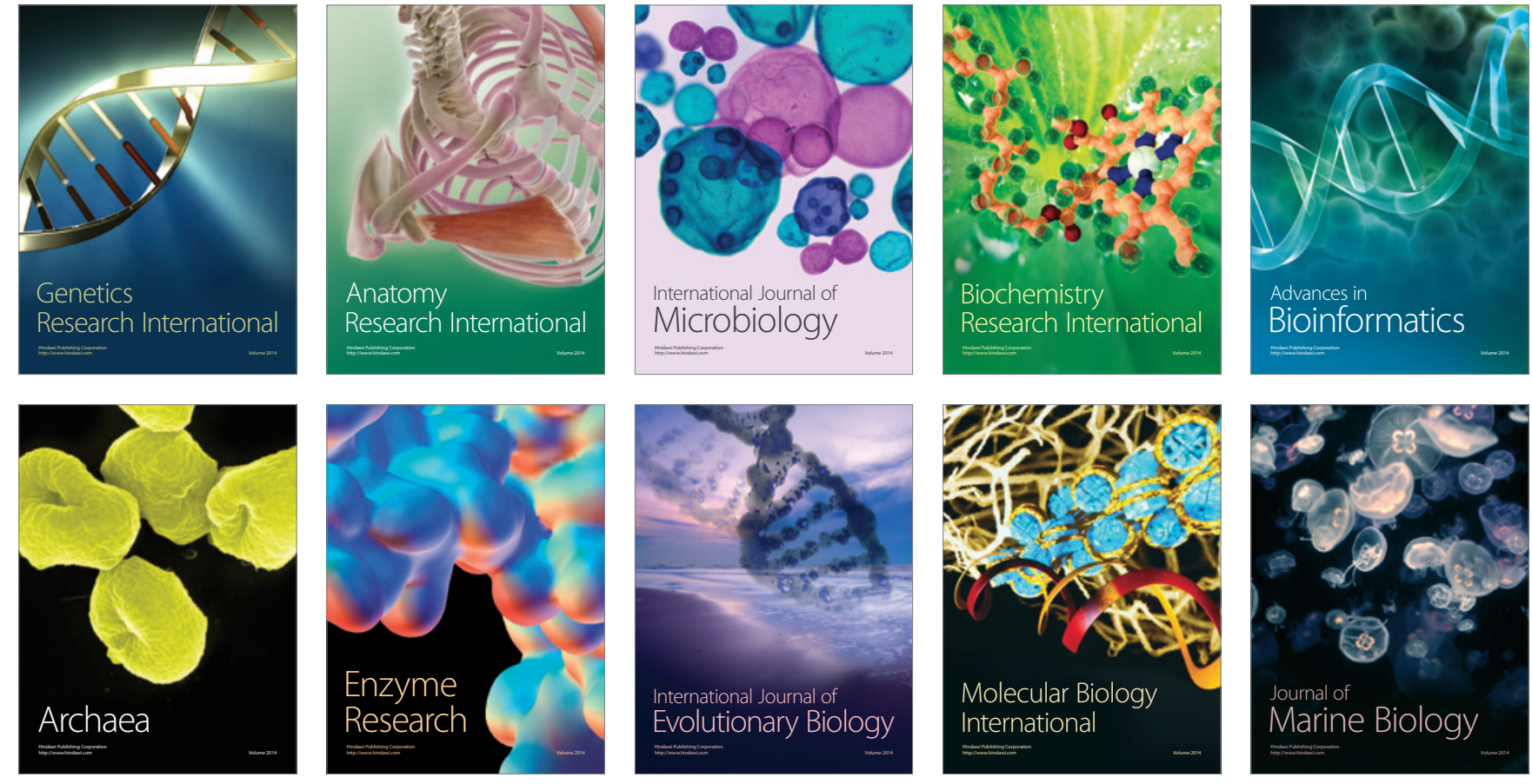